\title{
Evaluation of reference genes and normalization strategy for quantitative real-time PCR in human pancreatic carcinoma
}

\author{
Beatrice Mohelnikova-Duchonova ${ }^{\mathrm{a}, \mathrm{b}}$, Martin Oliverius ${ }^{\mathrm{c}}$, Eva Honsova ${ }^{\mathrm{d}}$ and Pavel Soucek $^{\mathrm{a}, *}$ \\ ${ }^{a}$ Department of Toxicogenomics, National Institute of Public Health, Prague, Czech Republic \\ ${ }^{\mathrm{b}}$ First Faculty of Medicine, Charles University in Prague, Czech Republic \\ ${ }^{c}$ Department of Transplantation Surgery, Institute of Clinical and Experimental Medicine, Prague, Czech Republic \\ ${ }^{\mathrm{d}}$ Department of Clinical and Transplantation Pathology, Institute of Clinical and Experimental Medicine, Prague, \\ Czech Republic
}

\begin{abstract}
Histologically verified pairs $(n=10)$ of pancreatic tumors and non-neoplastic tissues were used for quantitative real-time PCR and the stability of 24 reference genes was analyzed with geNorm and NormFinder software. Raw $\mathrm{C}_{q}$ values correlated with the degree of RNA degradation. This correlation was abolished by normalization to $\mathrm{C}_{q}$ of $18 \mathrm{~S}$ endogenous control gene. Both geNorm and NormFinder programs suggested EIF2B1, ELF1, MRPL19, and POP4 as the same most stable genes. We have thus identified suitable reference genes for future expression studies in pancreatic carcinoma. Normalization method reducing the effects of RNA degradation on the quality of results was also developed.
\end{abstract}

Keywords: Pancreas, carcinoma, transcript, quantification, reference gene, normalization

\section{Introduction}

Pancreatic cancer is the fourth leading cause of cancer death in the United States [1] as well as in the Czech Republic [2]. It has a dismal five-year survival less than 5\% [3], primarily related to the fact that diseasespecific symptoms occur late in the course of the disease. Pancreatic cancer belongs to one of the most difficult conditions to treat [4] and its etiology and molecular pathogenesis is still poorly understood.

Gene expression profiles are commonly used for identification of groups of genes involved in specific functional aspects of tumor biology and for the development of candidate biomarkers [5]. A number of methods have been developed to study gene expression.

* Address for correspondence: Pavel Soucek, PhD., Toxicogenomics Unit, National Institute of Public Health, Srobarova 48, Prague 10, 10042 Czech Republic. Tel.: +420 267082711; Fax: +420 267311236; E-mail: psoucek@szu.cz.
The relative quantification by real-time PCR method (qPCR) is adequate strategy for most purposes where investigation of physiological changes in gene expression levels is conducted [6-8]. There are several essential requirements for successful expression analysis. The first and crucial step is correct sample collection, handling and preparation [9]. By the time of diagnosis no more than $20 \%$ of patients with pancreatic carcinoma have surgically operable disease [10]. Thus, sampling in large specialized centers rather than in numerous smaller surgical departments is necessary for practical reasons. Typically, pancreatic tumors have low neoplastic cellularity and a predominance of nonneoplastic fibrous (or desmoplastic) stroma. This is rather unique to duct adenocarcinomas of the pancreas; in contrast to infiltrating carcinomas arising in other organs. To overcome this obstacle potentially leading to spurious results, two approaches are generally used. Firstly, microdissection or other methods of purification of the epithelial component are utilized. Second- 
Table 1

Characteristics of the patient population

\begin{tabular}{lccccccc}
\hline Sample & Date of diagnosis & Gender & Age at diagnosis & Surgery & Stage & Lymph nodes $^{\text {b }}$ & Grade $^{\text {a }}$ \\
\hline PCI2 & August 2008 & female & 54 & head/R0 & pT3N0M1 & $0 / 9$ & 3 \\
PCI4 & August 2009 & male & 69 & head/R0 & pT3N0Mx & $0 / 3$ & 3 \\
PCI5 & November 2009 & male & 63 & head/R0 & pT3N1Mx & $1 / 3$ & 3 \\
PCI7 & December 2009 & male & 46 & head/R0 & pT3N1Mx & $1 / 9$ & 3 \\
PCI8 & December 2009 & female & 74 & head/R0 & pT3N1Mx & $5 / 14$ & 3 \\
PCI9 & December 2009 & female & 54 & head/R1 & pT2N1Mx & $9 / 18$ & 2 \\
PCI10 & December 2009 & female & 53 & head/R0 & pT4N1Mx & $1 / 24$ & 2 \\
PCI12 & January 2010 & female & 71 & head/R0 & pT2N0Mx & $0 / 14$ & 2 \\
PCI15 & February 2010 & male & 72 & head/R0 & pT2N0Mx & $0 / 14$ & 2 \\
PCI17 & May 2010 & female & 65 & tail/R0 & pT3N1Mx & $1 / 23$ & 3 \\
\hline
\end{tabular}

${ }^{a}$ Anatomical localization of tumor/radicality of surgery; ${ }^{b}$ Number of nodes with histologically confirmed metastasis/number of evaluated nodes.

ly, differences between macrodissected pancreatic tumors and non-neoplastic control tissues and eventually specimen from patients with chronic pancreatitis as an intermediate group are analyzed with stable cell lines as correctors [11]. In pancreatic tissues specifically, high-quality RNA preparation as the prerequisite condition for successful analysis presents an extremely difficult challenge. Subsequent assessment of RNA quality and quantity is the next critical step in expression analysis [6]. Pancreatic tissues contain a large amount of endogenous RNAses. RNAses are a major secretory product of normal pancreatic acinar cells and cause extensive degradation of mRNA in pancreatic tissues. Moreover, there is a frequent loss of acinar cells during development of infiltrating pancreatic cancers due to atrophy or destruction of the gland by the tumor growth [11]. The content of RNAse secreting cells thus may vary among tumors. Thus for laboratories aiming at expression profiling of pancreatic cancer, it is essential to introduce specific protocol for the handling of a pancreatic specimen, RNA isolation procedure and rigorous control of RNA and cDNA quality and quantity. The appropriate choice of internal standards (reference genes) is critical for qPCR performance. Ideally, the internal standards should be constitutively expressed in all cell types under study. Internal standards should also be independent of experimental conditions and unaffected by human disease conditions. Formerly, a number of housekeeping genes, which are necessary for basic cell survival, like glucose-6-phosphate dehydrogenase $(G A P D H)$, ribosomal RNA subunits (18S and 28S rRNA), $\beta$-actin or cyclophilins were used as reference genes. However, it has become clear that these highly popular reference genes show distinct differences in gene expression in certain tissue types and considerably vary between normal and malignant tissues [12-14].

The purpose of our study was to assess performance of 24 reference genes by qPCR in a series of 10 mac- rodissected pairs of pancreatic carcinomas and adjacent non-neoplastic tissues. The robustness of qPCR analysis on samples with quality unavoidably compromised by RNA degradation was assessed as a major endpoint.

\section{Material and methods}

\subsection{Samples}

Tissue specimens were obtained from 10 surgically treated pancreatic carcinoma patients diagnosed over a period between August 2008 and May 2010. The resection specimens were immediately transferred from the Surgery to the Pathology Department, then macrodissected, snap-frozen in liquid nitrogen and stored at $-80^{\circ} \mathrm{C}$ until RNA preparation. Histological diagnoses of pancreatic carcinomas including types, stages, and grades of the tumors were performed according to AJCC rules for classification [15]. Only histologically confirmed tumor and non-neoplastic tissue samples were used for RNA analysis. The following data on patients were retrieved from medical records: age, sex, date of diagnosis, pTNM stage, histological type and grade of the tumor (Table 1). All patients were asked to read and sign an informed consent in accordance with the requirements of the Ethical Commission of the Institute of Clinical and Experimental Medicine in Prague.

\subsection{Isolation of total RNA and cDNA synthesis}

Tissue samples were homogenized by mechanical disruption using Precellys instrument (Bertin Technologies, Montigny-le-Bretonneux, France) at a speed of 6,500 for $15 \mathrm{sec}$. Total RNA was isolated using Trizol Reagent according to manufacturer's protocol 
Table 2

Information about reference genes and the respective Assays

\begin{tabular}{|c|c|c|c|c|}
\hline Gene symbol (ID) & Assay ID & Location of probe & Amplicon length (bp) & Gene name \\
\hline GAPDH (2597) & Hs02758991_g1 & 3'-most, exon 7-8 boundary & 93 & $\begin{array}{l}\text { glyceraldehyde-3-phosphate } \\
\text { dehydrogenase }\end{array}$ \\
\hline HPRT1 (3251) & Hs99999909_m1 & 3'-most, exon 6-7 boundary & 100 & $\begin{array}{l}\text { hypoxanthine phosphoribosyltrans- } \\
\text { ferase } 1\end{array}$ \\
\hline GUSB (2990) & Hs99999908_m1 & 3'-most, exon $11-12$ boundary & 81 & glucuronidase, beta \\
\hline АCTB (60) & Hs00357333_g1 & exon $1-2$ boundary & 77 & actin, beta \\
\hline$B 2 M(567)$ & Hs99999907_m1 & 3'-most, exon $2-3$ boundary & 75 & beta-2-microglobulin \\
\hline$H M B S(3145)$ & Hs00609297_m1 & 3'-most, exon 1-2 boundary & 64 & hydroxymethylbilane synthase \\
\hline IPO8 (10526) & Hs00183533_m1 $1^{\mathrm{a}}$ & 3'-most, exon $20-21$ boundary & 71 & importin 8 \\
\hline PGK1 (5230) & Hs00943178_g $1^{\mathrm{a}}$ & 3'-most, exon 5-6 boundary & 73 & phosphoglycerate kinase 1 \\
\hline$T B P(6908)$ & Hs00427621_m1 $1^{\mathrm{a}}$ & exon 3-4 boundary & 65 & TATA box binding protein \\
\hline TFRC (7037) & Hs99999911_m1 & exon 14 & 105 & transferrin receptor \\
\hline YWHAZ (7534) & Hs00237047_m1 & exon $1-2$ boundary & 70 & $\begin{array}{l}\text { tyrosine 3-monooxygenase/trypto- } \\
\text { phan 5-monooxygenase activation } \\
\text { protein, zeta polypeptide }\end{array}$ \\
\hline PPIA (5478) & Hs01565700_g1 & exon 3-4 boundary & 94 & peptidylprolyl isomerase A \\
\hline POLR2A (5430) & Hs00172187_m $1^{\mathrm{a}}$ & 3'-most, exon $1-2$ boundary & 61 & $\begin{array}{l}\text { polymerase (RNA) II (DNA direct- } \\
\text { ed) polypeptide A }\end{array}$ \\
\hline GADD45A (1647) & Hs00169255_m1 ${ }^{\mathrm{a}}$ & exon 3-4 boundary & 123 & $\begin{array}{l}\text { growth arrest and DNA-damage- } \\
\text { inducible, alpha }\end{array}$ \\
\hline EIF2B1 (1967) & Hs00426752_m1 ${ }^{\mathrm{a}}$ & 3'-most, exon 4-5 boundary & 75 & $\begin{array}{l}\text { eukaryotic translation initiation fac- } \\
\text { tor } 2 \mathrm{~B} \text {, subunit } 1 \text { alpha }\end{array}$ \\
\hline$A B L 1(25)$ & Hs00245445_m $1^{\mathrm{b}}$ & exon 3-4 boundary & 91 & $\begin{array}{l}\mathrm{c} \text {-abl oncogene } 1 \text {, non-receptor ty- } \\
\text { rosine kinase }\end{array}$ \\
\hline ELF1 (1997) & Hs00152844_m1 $1^{\mathrm{a}}$ & 3'-most, exon $2-3$ boundary & 76 & E74-like factor 1 \\
\hline MRPL19 (9801) & Hs00608519_m1 ${ }^{\mathrm{a}}$ & exon $2-3$ boundary & 72 & $\begin{array}{l}\text { mitochondrial ribosomal protein } \\
\text { L19 }\end{array}$ \\
\hline PES1 (23481) & Hs00362795_g $1^{\mathrm{a}}$ & 3'-most, exon 13-14 boundary & 56 & pescadillo homolog 1 \\
\hline RPL3O (6156) & Hs00265497_m1 $1^{\mathrm{a}}$ & exon $4-5$ boundary & 149 & ribosomal protein L30 \\
\hline RPS17 (6218) & Hs02386586_g1 & exon 2-3 boundary & 88 & ribosomal protein $\mathrm{S} 17$ \\
\hline POP4 (10775) & Hs00198357_m1 $1^{\mathrm{a}}$ & exon 3-4 boundary & 68 & $\begin{array}{l}\text { processing of precursor } 4 \text {, ribonu- } \\
\text { clease P/MRP subunit }\end{array}$ \\
\hline PSMC4 (5704) & Hs00197826_m1 $1^{\mathrm{a}}$ & exon 6-7 boundary & 83 & proteasome $26 \mathrm{~S}$ subunit, ATPase, 4 \\
\hline 18S (100008588) & Hs03928990_g $1^{\mathrm{a}}$ & not applicable & 61 & 18S ribosomal RNA \\
\hline
\end{tabular}

a assay recommended by the manufacturer (for criteria see www.appliedbiosystems.com);

${ }^{\mathrm{b}}$ Based on assay re-evaluation in August 2010 with NCBI Entrez Gene annotations, this assay may detect transcript(s) from off target gene(s) (see. www.appliedbiosystems.com).

(Invitrogen, Carlsbad, CA) and stored at $-80^{\circ} \mathrm{C}$ in aliquotes. RNA quantity was assessed in duplicates by Quant-iT ${ }^{\mathrm{TM}}$ RNA Assay Kit (Invitrogen) using Infinite M200 fluorescence reader (Tecan, Vienna, Austria). RNA quality was assessed by measurement of the RNA Integrity Number (RIN) using Agilent 2100 Bioanalyzer (Agilent Technologies, Santa Clara, CA) and RNA Nano 6000 LabChip kit (Agilent Technologies). RNA with RIN above 2.0 was used for further processing. cDNA was synthesized using RevertAid ${ }^{\mathrm{TM}}$ First Strand cDNA Synthesis Kit with random hexamer primers according to manufacturer' protocol (MBI Fermentas, Vilnius, Lithuania). For cDNA synthesis $2 \mu \mathrm{g}$ of total RNA were reverse-transcribed in a final reaction volume of $80 \mu$ l, i.e. $25 \mathrm{ng} / \mu \mathrm{l}$ final concentration of cDNA at theoretical 100\% efficiency. Quantity and quality of cDNA in terms of DNA contamination was then confirmed by PCR amplification of ubiqui- tin $\mathrm{C}$ fragment discriminating between products from cDNA (190 bp) and from genomic DNA (1,009 bp) as described previously [16]. All cDNA samples that were free of DNA contamination (absence of 1,009 bp band in samples incubated without reverse transcriptase) were stored at $-20^{\circ} \mathrm{C}$ until analysis.

\subsection{Quantitative real-time PCR}

qPCR was performed in 7500 Real-Time PCR System by help of TaqMan ${ }^{\circledR}$ Custom Plates (Applied Biosystems, Foster City, CA). For analysis of reference genes $4 \times 24$ well format was used comprising of TaqMan ${ }^{\circledR}$ Gene Expression Assays with optimized primer and probe sets (Table 2). The following criteria were applied to the selection of TaqMan ${ }^{\circledR}$ Gene Expression Assays: i/ exon-exon boundaries span where possible in order to minimize signals from traces of 


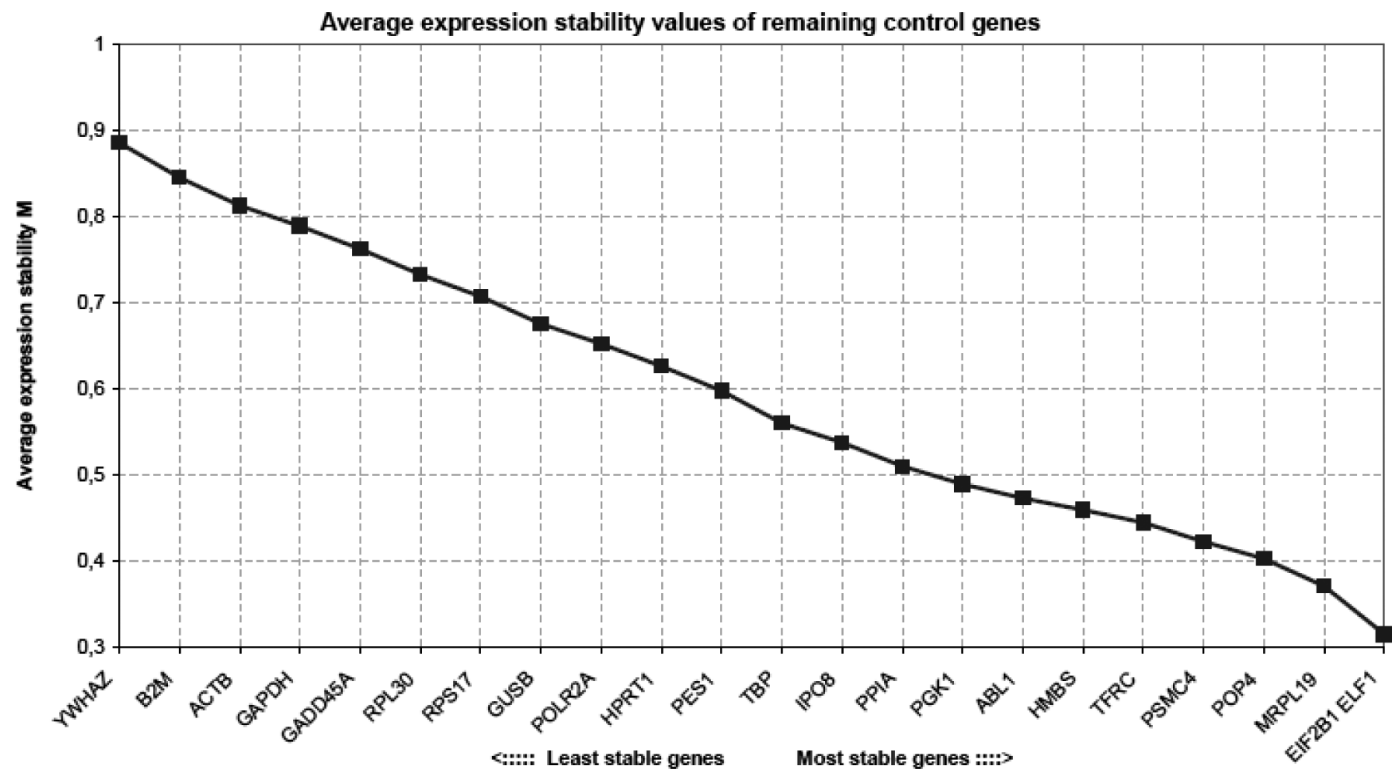

Fig. 1. Output from geNorm. Legend: Relative quantities for the respective genes described in Table 2 were input to geNorm program. The calculation of relative quantities is described in Material and Methods. The figure represents output from the program where genes with the lowest average expression stability value (M) are the most stable ones and may serve as suitable reference genes for study of the same type of samples. Genes located in the far right part of the $\mathrm{x}$-axis were selected as candidates for reference genes. The underlying principles and calculations are described in Vandesompele et al. [17].

contaminating DNA, ii/ as short as possible amplicons and iii/ location near to 3'-end of the transcript to reduce influence of RNA quality on qPCR. Priority was given to assays from the validated endogenous control set. The list of reference genes and respective assays is given in Table 2. Each reaction contained in total $20 \mu \mathrm{l}$ of premixed cDNA and $2 \mathrm{x}$ TaqMan ${ }^{\circledR}$ Gene Expression Master Mix (Applied Biosystems) in 1:1 ratio. The amount corresponding to $25 \mathrm{ng}$ of total RNA used for cDNA synthesis was loaded per each sample well. Cycling parameters were: $2 \mathrm{~min}$. at $50^{\circ} \mathrm{C}$ and initial denaturation at $95^{\circ} \mathrm{C}$ for $10 \mathrm{~min}$, followed by $50 \mathrm{cy}$ cles consisting of denaturation at $95^{\circ} \mathrm{C}$ for $15 \mathrm{sec}$ and annealing at $60^{\circ} \mathrm{C}$ for $60 \mathrm{sec}$.

\subsection{Analyses of stability of reference genes}

Firstly, $\Delta \mathrm{C}_{q}$ was calculated for each sample where $\Delta \mathrm{C}_{q}=\mathrm{C}_{q}$ (sample) $-\mathrm{C}_{q}$ (calibrator, i.e. non-neoplastic sample with the lowest average $\mathrm{C}_{q}$ from all tested samples, i.e. ZPI5). Then relative quantity $\mathrm{Q}=\mathrm{E}^{\Delta C q}$ where efficiency $\mathrm{E}$ was considered as $100 \%$, i.e. $2^{\Delta C q}$ value was calculated and used for analysis of stability of reference genes. The study design adhered to the MIQE Guidelines (Minimum Information for Publication of Quantitative Real-Time PCR Experiments) published in 2009 [9]. geNorm version 3.5 of March 2007 [17] and NormFinder version 19 of June 2009 [18] software programs were used for evaluation of stability of reference genes according to manuals available at the website for their download. Differences between groups were analyzed by non-parametric Wilcoxon test and correlations were analyzed by non-parametric Spearman's test using SPSS version 15.0 software.

\section{Results}

\subsection{RNA quantity and quality assessment}

The total RNA was isolated from surgically removed tumor and non-neoplastic tissues of 10 patients with pancreatic carcinoma diagnosis. The median RIN of tumor and non-neoplastic tissue samples was $6.5 \pm 1.0$ (range 4.2-7.4) and of 3.3 $\pm 1.6(2.1-6.5$ ), respectively. RIN values differed significantly between tumors and non-neoplastic tissues ( $p=0.005$, Wilcoxon test). cDNA was synthesized using $2 \mu \mathrm{g}$ of total RNA. Samples free of genomic DNA contamination as assessed by PCR for ubiquitin $\mathrm{C}$ fragment were used for subsequent analyses. 


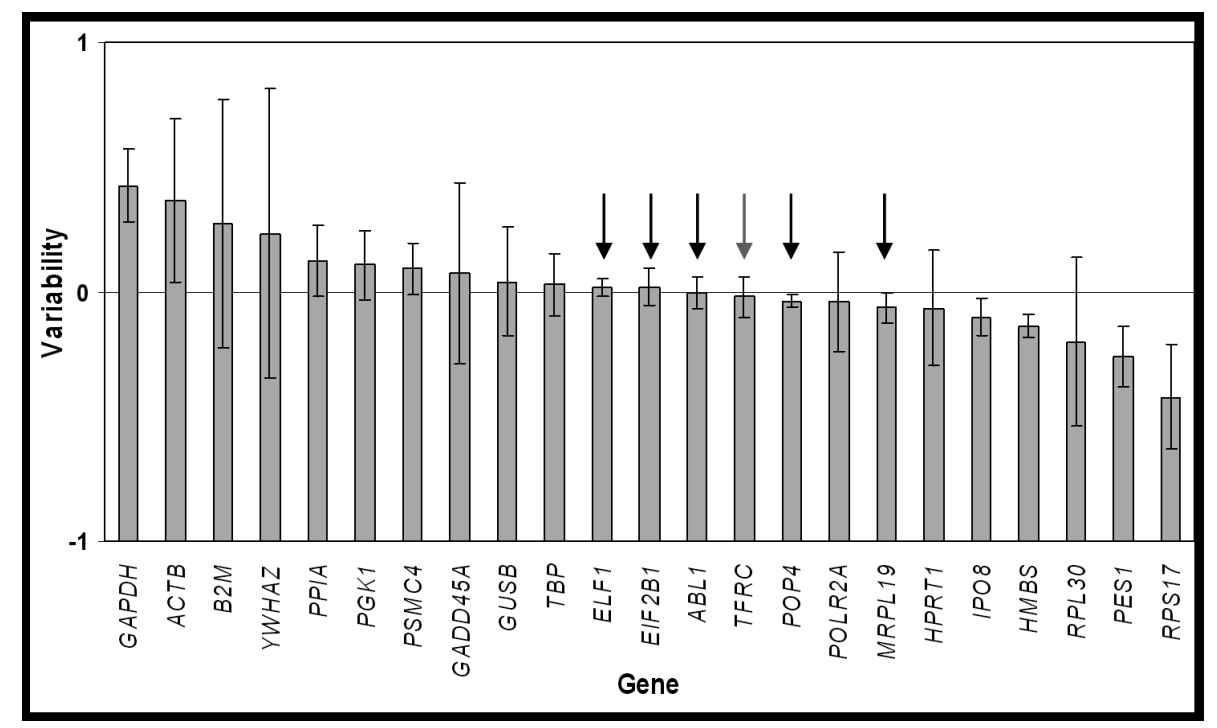

Fig. 2. Output from NormFinder. Legend: Relative quantities for the respective genes described in Table 2 were input to NormFinder program. The calculation of relative quantities is described in Material and Methods. The figure represents inter-group and intra-group variability among the tested samples. Candidate genes with an inter-group variation as close to zero as possible, and at the same time with the smallest errors bars possible were selected as suitable reference genes. These genes are highlighted by arrows in the figure. TFRC as alternative reference gene is highlighted by the grey arrow. The model and statistical framework underlying "NormFinder" are described in Andersen et al. [18].

\subsection{Quantitative real-time $P C R$}

We analyzed transcript levels of 24 candidates for reference genes for qPCR studies of pancreatic tumor and non-neoplastic tissue samples. The mean raw $\mathrm{C}_{q}$ values for all genes except $18 \mathrm{~S}$ in tumors and nonneoplastic tissues were $27.06 \pm 3.47$ and $27.27 \pm 2.88$, respectively. The median raw $\mathrm{C}_{q}$ values in tumors and non-neoplastic tissues were 27.02 and 27.24, respectively. The raw $\mathrm{C}_{q}$ values were highly dependent on the degree of RNA degradation represented by RIN. Significant correlation of RIN with the mean of raw $\mathrm{C}_{q}$ for all studied genes except $18 \mathrm{~S}$ was observed in control tissues ( $p=0.010$, Fig. 3A). Non-significant trend was found in tumors ( $p=0.074$, Fig. 3A) and the effect became highly significant when all tissues were analyzed together $\left(\mathrm{R}^{2}=0.57, p<0.001\right.$, data not shown). After normalization of data by calculation of $\mathrm{C}_{q}$ (reference gene)/ $\mathrm{C}_{q}(18 \mathrm{~S}$ endogenous control gene) none of the correlations with RIN remained significant ( $p=0.253$ in controls, $p=0.301$ in tumors, and $p=$ 0.841 in all tissues; Fig. 3B).

\subsection{Identification of reference genes}

The relative quantity $\mathrm{Q}$ defined in Materials and Methods was used for analysis of stability of reference genes by geNorm and NormFinder. Sample ZPI5 with average $\mathrm{C}_{q}=25.27 \pm 2.44$ and $\mathrm{RIN}=5.3$ was used as calibrator. Both programs showed similar results, i.e. identified the same genes among the five most stable genes (EIF2B1, ELF1, MRPL19 and POP4) and suggested 2-3 reference gene combinations as sufficient for qPCR in pancreatic carcinoma. qPCR efficiency was then evaluated for the four best reference genes, i.e. EIF2B1, ELF1, POP4 and MRPL19 by assessment of serial dilutions of calibrator sample (ZPI5). Analysis of the efficiency, $\mathrm{R}^{2}$, and slope of calibration curves and $\mathrm{C}_{q}$ in non-template controls (NTCs) proved that all genes were suitable for further use in $\mathrm{qPCR}$ as reference genes (Table 3).

\section{Discussion}

Research of pancreatic cancer is hindered by difficulties with the recruitment of pancreatic cases with brief survival and poor performance status. Additionally, in inoperable patients (the majority in pancreatic cancer) the verification of diagnosis is complicated by the lack of pathological specimen. Moreover, pancreatic specimens present a hurdle in isolation of intact RNA due to the presence of high amounts of RNAses. Therefore, it is essential to validate the protocol of sample handling and RNA isolation from pancreatic tissues for qPCR purposes and minimize the effect of poor RNA quality. 

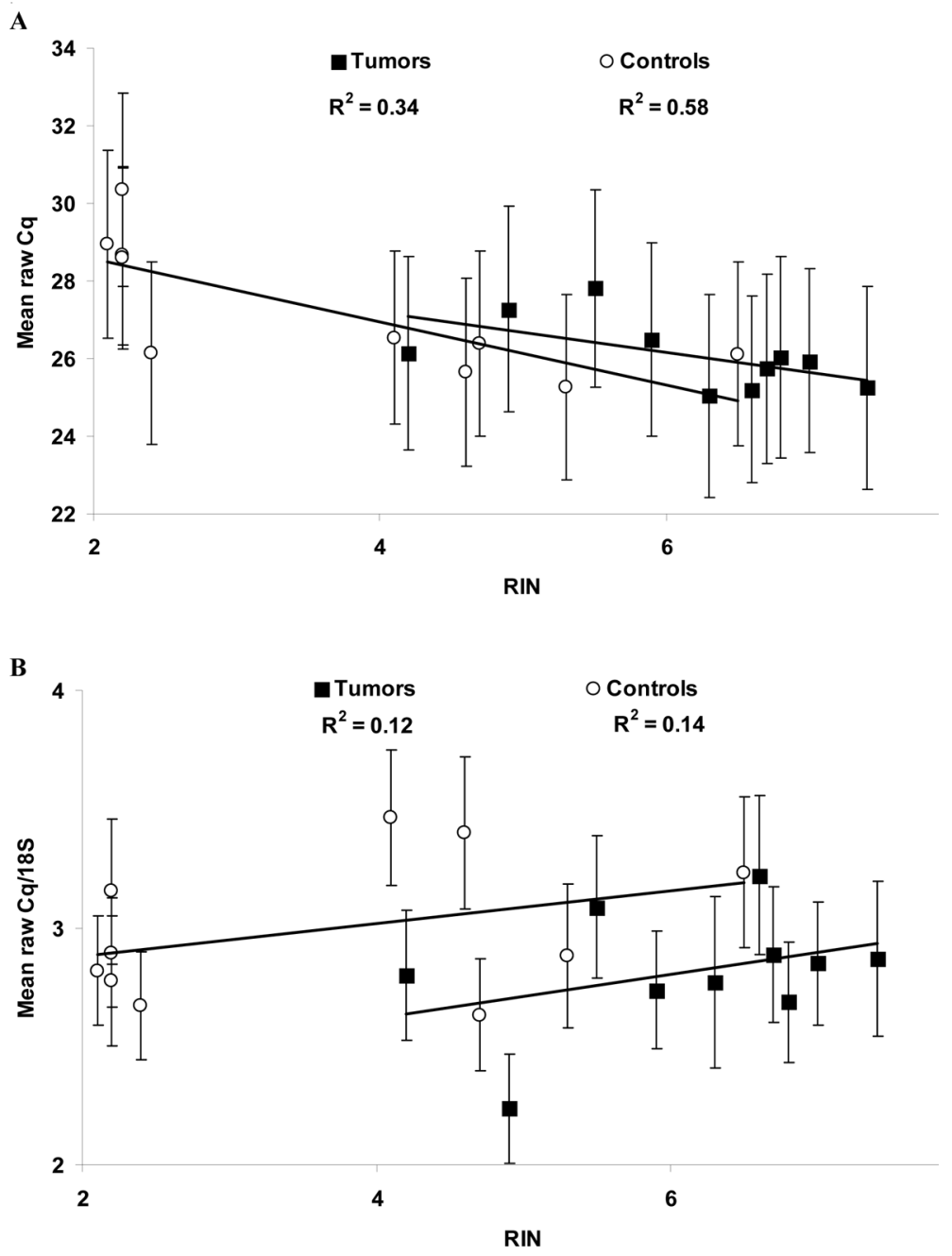

Fig. 3. Correlations between RIN and levels of reference genes. Legend: Mean \pm S.D. of raw Cq of all studied genes except $18 \mathrm{~S}$ for each sample was plotted against RIN (A). Mean \pm S.D. of raw Cq/18S was plotted against RIN (B). Correlation coefficients and significances were calculated by the non-parametric Spearman test.

The aim of our study was to identify the most stable expressing endogenous control genes in tissue specimens from pancreatic cancer patients as potential reference genes for qPCR. Special attention was paid to the evaluation of the effect of RNA stability and assessment whether or not proper normalization can influence this effect.

We have found that under the same standard conditions of sample collection (tumor and non-neoplastic tissues macrodissected and snap frozen at the same time), storage and RNA isolation, the quality of RNA (by RIN comparison) from non-neoplastic pancreatic specimens is considerably lower than that from the respective tumor samples $(p=0.005)$. This was true for all of the inspected $(n=10)$ sample pairs and therefore we can speculate that the RNAse content may generally be higher in non-neoplastic tissues. It is assumed that the ischemia time from ligation of the duodenal/pancreatic vessels to the withdrawal of tissue for analysis is too long and causes massive RNA degradation. Since this ischemia time is an unalterable component of the operation, RNA analyses of pancreatic tissues present very difficult procedure [19]. For isolation of total RNA, Trizol Reagent-based procedure was used according to the recent literature [20,21]. Thus, the method of RNA isolation most probably did not cause the observed differences in RNA stability between samples. Our observation confirmed the previously published results that RNA isolated from solid tissues usually has the RIN between 6 and 8 , but that from 
Table 3

Performance of reference genes in qPCR

\begin{tabular}{lcccc}
\hline Sample & EIF2B1 & MRPL19 & ELF1 & POP4 \\
\hline NTCs & $>40$ & $>40$ & $>40$ & $>40$ \\
Standard 1 & $22.02 \pm 0.03$ & $24.51 \pm 0.01$ & $19.59 \pm 0.01$ & $23.29 \pm 0.02$ \\
Standard 2 & $23.24 \pm 0.03$ & $25.78 \pm 0.04$ & $20.59 \pm 0.02$ & $24.53 \pm 0.02$ \\
Standard 3 & $24.52 \pm 0.07$ & $27.13 \pm 0.04$ & $21.75 \pm 0.02$ & $26.11 \pm 0.01$ \\
Standard 4 & $26.81 \pm 0.04$ & $29.48 \pm 0.12$ & $24.14 \pm 0.07$ & $28.28 \pm 0.04$ \\
Standard 5 & $29.24 \pm 0.04$ & $31.93 \pm 0.14$ & $26.68 \pm 0.05$ & $30.62 \pm 0.08$ \\
Efficiency & $98 \%$ & $94 \%$ & $98 \%$ & $96 \%$ \\
Slope & -3.38 & -3.48 & -3.37 & -3.43 \\
$\mathrm{R}^{2}$ & 0.999 & 0.999 & 0.999 & 0.998 \\
\hline
\end{tabular}

cDNA of sample ZPI5 used for construction of the calibration curve was diluted 5-times (standard 1), 10-times (standard 2), 25-times (standard 3), 125-times (standard 4) and 625-times (standard 5). NTC (non-template control) consisted of water instead of cDNA. Samples were analyzed in triplicates (mean $\mathrm{C}_{q} \pm$ S.D. shown).

gastrointestinal tract has great RIN variation with RIN around 4 under experimental conditions with bovine organs [22]. The relatively low RIN values also precluded laser capture microdissection, which lowers the RIN by 1-2 points in pancreatic specimens [21]. Fleige et al. [6] found a significant impact of RIN on results of expression analysis, mainly the quantification cycle $\left(\mathrm{C}_{q}\right.$, formerly $\left.\mathrm{C}_{t}\right)$ and minor effect on PCR efficiency. Antonov et al. [23] demonstrated in a biologically homogenous system of intact and partially hydrolyzed RNA derived from a cell line that degradation-related shifts of $\mathrm{C}_{q}$ values can be compensated by calculating delta $\mathrm{C}_{q}$ values between test genes and the mean $\mathrm{C}_{q}$ values of several reference genes. These delta $\mathrm{C}_{q}$ values were less sensitive to fragmentation of the RNA and were unaffected by varying amounts of input RNA [23]. In our experimental setting RIN significantly correlated with mean raw $\mathrm{C}_{q}$ values of 24 tested genes. Therefore, we used normalization of data by calculation of $\mathrm{C}_{q}$ (reference gene)/ $\mathrm{C}_{q}(18 \mathrm{~S}$ endogenous control gene). This normalization abolished the observed correlation with RIN. Thus, we demonstrated that the degradationrelated $\mathrm{C}_{q}$ shifts caused by RNA fragmentation can be compensated by normalizing of the $\mathrm{C}_{q}$ of the reference gene and potentially the gene of interest to $\mathrm{C}_{q}$ of the endogenous $18 \mathrm{~S}$ control gene.

We have screened 24 candidates for reference genes selected preferably from commercially available validated endogenous controls. There are several approaches for selection of most stable reference genes for qPCR in the literature, including the use of various programs for evaluation of results. In order to provide an overview of their performance, we have used two examples of the most frequently used software (NormFinder and geNorm) for evaluation of results. Both of these programs gave consistent results, although when rigor- ously evaluated, the most stable genes were not picked in the same order. However, EIF2B1, ELF1, MRPL19 and $P O P 4$ were among the first five most stable genes in both NormFinder and geNorm output. The amplification efficiency of target genes and reference genes should be tested before their use in relative quantification by qPCR. Slope and linearity of calibration curves should be analyzed as well [24]. We have shown that all selected genes perform well in qPCR (efficiency in the range $90-110 \%, \mathrm{R}^{2} \geqslant 0.998$ ) and thus we recommend the use of these genes as reference genes for qPCR in pancreatic cancer research. Rubie et al. [25] tested 21 reference genes by qPCR in five gastrointestinal cancers. Tumor and normal tissues from 10 patients with pancreatic carcinoma were followed, amongst others. 18S-RNA, glutaminyl-tRNA synthetase (QARS), phosphomannomutase $(P M M 1)$, RNA polymerase II polypeptide $\mathrm{L}(P O L R 2 L)$ and $\beta$-glucuronidase $(G U S B)$ showed the most stable expression. Analysis of agarose gel electrophoretic profiles was used as RNA quality control instead of RIN. In this study the comparative $\Delta \mathrm{C}_{q}$ method was used. Results were then transformed to linear form by calculation of $2-\Delta \mathrm{C}_{q}$ (mean $\mathrm{C}_{q}$ pathological tissue-mean $\mathrm{C}_{q}$ calibrator) [25]. Our study of the same size $(n=10)$ considered a bit different selection of genes ( 7 of 21 previously used genes were included in our study). However, GUSB was not confirmed among the five most stable genes by any of the programs used in our study. HPRT, GAPDH, PGK1, $A C T B$, and $B 2 M$ did not perform well in both our and the previous study [25].

The published microarray data contain more than 2,500 potential reference genes [26]. It seems intriguing to compare the results of this study with appropriate selection of the most stable reference genes from microarray data. However, the recently discussed incom- 
plete information on tissue composition and/or the use of well-defined tissues severely hampers any meaningful microarray data analysis and conclusive data interpretation [27]. In context with the fact that repeatability of microarray data is considered limited [28] such comparison may be an interesting goal for future investigations after major shortcomings are resolved.

In conclusion, we have identified four potential candidates as reference genes for future qPCR studies in pancreatic cancer research. We also suggest the normalization method which may reduce the effect of poor RNA quality on the quality of results.

\section{Acknowledgements}

This study was supported by grants of Grant Agency of the Ministry of Health of the Czech Republic, grant no. 9799-4 and 10230-3.

\section{References}

[1] A. Jemal, R. Seigel, J. Xu et al., Cancer statistics 2010, CA Cancer J Clin 60 (2010), 277-300.

[2] IHIS CR, Cancer Incidence 2006 in the Czech Republic, Czech Republic, 2009.

[3] M. Hidalgo, Pancreatic cancer, New Engl J Med 362 (2010), 1605-1617.

[4] M.J. Moore, D. Goldstein, J. Hamm et al., Erlotinib plus gemcitabine compared with gemcitabine alone in patients with advanced pancreatic cancer, a phase III trial of the National Cancer Institute of Canada Clinical Trials Group, J Clin Oncol 25 (2007), 1960-1966.

[5] C. Rosty, T. Ueki, P Argani et al., Overexpression of S100A4 in pancreatic ductal adenocarcinomas is associated with poor differentiation and DNA hypomethylation, Am J Pathol 160 (2002), 45-50.

[6] S. Fleige, V. Walf, S. Huch et al., Comparison of relative mRNA quantification models and the impact of RNA integrity in quantitative real-time RT-PCR, Biotechnol Lett 28 (2006), 1601-1613.

[7] M. Hubackova, R. Vaclavikova, M. Mrhalova et al., NAD(P) $\mathrm{H}$, quinone oxidoreductase 1 Pro187Ser polymorphism and expression do not co-segregate with clinico-pathological characteristcs of human mammary tumors, Pharmacogenet Genomics 19 (2009), 505-512.

[8] M. Hubackova, R. Vaclavikova, M. Ehrlichova et al., Association of superoxide dismutases and $\mathrm{NAD}(\mathrm{P}) \mathrm{H}$ oxidoreductases with prognosis of patients with breast carcinomas, Int $J$ Cancer (2011), Feb 23. doi, 10.1002/ijc. 26006.

[9] S.A. Bustin, V. Benes, J.A. Garson et al., The MIQE guidelines, minimum information for publication of quantitative real-time PCR experiments, Clin Chem 55 (2009), 611-622.

[10] C. Sharma, K.M. Eltawil, P.D. Renfrew et al., Advances in diagnosis, treatment and palliation of pancreatic carcinoma: 1990-2010, World J Gastroenterol 17 (2011), 867-897.

[11] F. Vilardell and C.A. Iacobuzio-Donahue, Cancer gene profiling in pancreatic cancer, Methods Mol Biol 576 (2010), 279292.
[12] H. Zhong and J.W. Simons, Direct comparison of GAPDH, beta-actin, cyclophilin, and 28S rRNA as internal standards for quantifying RNA levels under hypoxia, Biochem Biophys Res Commun 259 (1999), 523-526.

[13] C. Blanquicett, M.R. Johnson, M. Heslin et al., Housekeeping gene variability in normal and carcinomatous colorectal and liver tissues, applications in pharmacogenomic gene expression studies, Anal Biochem 303 (2002), 209-214.

[14] V.P. Mane, M.A. Heuer, P. Hillyer et al., Systematic method for determining an ideal housekeeping gene for real-time PCR analysis, J Biomol Tech 19 (2008), 342-347.

[15] F.L. Greene, A. Trotti III, A.G. Fritz, C.C. Compton, D.R. Byrd and S.B. Edge, eds, AJCC Cancer Staging Handbook 7th ed., 2010, American Joint Committee on Cancer, Chicago, IL, USA, 2009.

[16] P. Soucek, P. Anzenbacher, I. Skoumalova et al., Expression of cytochrome P450 genes in CD34+ hematopoietic stem and progenitor cells, Stem Cells 23 (2005), 1417-1422.

[17] J. Vandesompele, K. De Preter, F. Pattyn et al., Accurate normalization of real-time quantitative RT-PCR data by geometric averaging of multiple internal control genes, Genome Biol 3 (2002), research0034.1-0034.11.

[18] C.L. Andersen, J.L. Jensen and T.F. Ørntoft, Normalization of Real-Time Quantitative Reverse Transcription-PCR Data, A Model-Based Variance Estimation Approach to Identify Genes Suited for Normalization, Applied to Bladder and Colon Cancer Data Sets, Cancer Res 64 (2004), 5245-5250.

[19] S.T. Mees, W.A. Mardin, C. Wendel et al., EP300-a miRNAregulated metastasis suppressor gene in ductal adenocarcinomas of the pancreas, Int J Cancer 126 (2010), 114-124.

[20] D. Li, W. Ren, X. Wang et al., A modified method using TRIzol reagent and liquid nitrogen produces high-quality RNA from rat pancreas, Appl Biochem Biotechnol 158 (2009), 253-261.

[21] U. Rudloff, U. Bhanot, W. Gerald et al., Biobanking of human pancreas cancer tissue: impact of ex-vivo procurement times on RNA quality, Ann Surg Oncol 17 (2010), 2229-2236.

[22] S. Fleige and M.W. Pfaffl, RNA integrity and the effect on the real-time qRT-PCR performance, Mol Aspects Med 27 (2006), 126-139.

[23] J. Antonov, D.R. Goldstein, A. Oberli et al., Reliable gene expression measurements from degraded RNA by quantitative real-time PCR depend on short amplicons and a proper normalization, Lab Invest 85 (2005), 1040-1050.

[24] K.J. Livak and T.D. Schmittgen, Analysis of relative gene expression data using real time quantitative PCR and the 2deltaCt methods, Methods 25 (2001), 402-408.

[25] C. Rubie, K. Kempf, J. Hans et al., Housekeeping gene variability in normal and cancerous colorectal, pancreatic, esophageal, gastric and hepatic tissues, Mol Cell Probes 19 (2005), 101-109.

[26] C.W. Chang, W.C. Cheng, C.R. Chen et al., Identification of human housekeeping genes and tissue-selective genes by microarray meta-analysis, PLoS One 6 (2011), e22859.

[27] E. Gadaleta, R.J. Cutts, G.P. Kelly et al., A global insight into a cancer transcriptional space using pancreatic data: importance, findings and flaws, Nucleic Acids Res 39 (2011), 7900-7907.

[28] J.P. Ioannidis, D.B. Allison, C.A. Ball et al., Repeatability of published microarray gene expression analyses, Nat Genet 41 (2009), 149-155. 


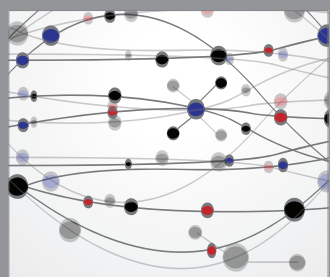

The Scientific World Journal
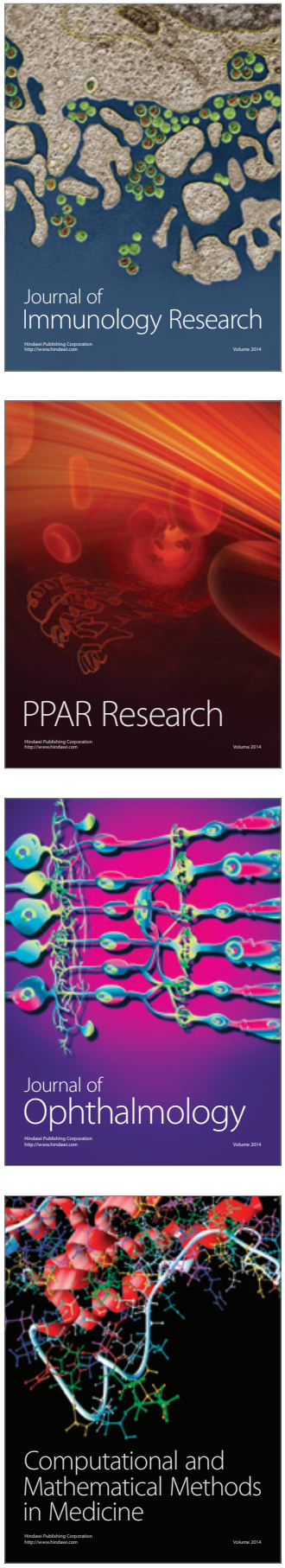

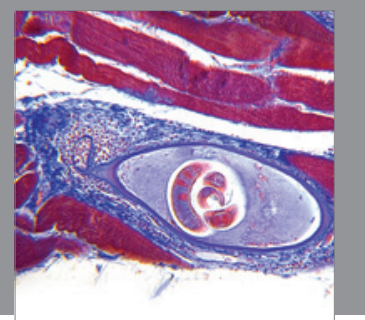

Gastroenterology

Research and Practice
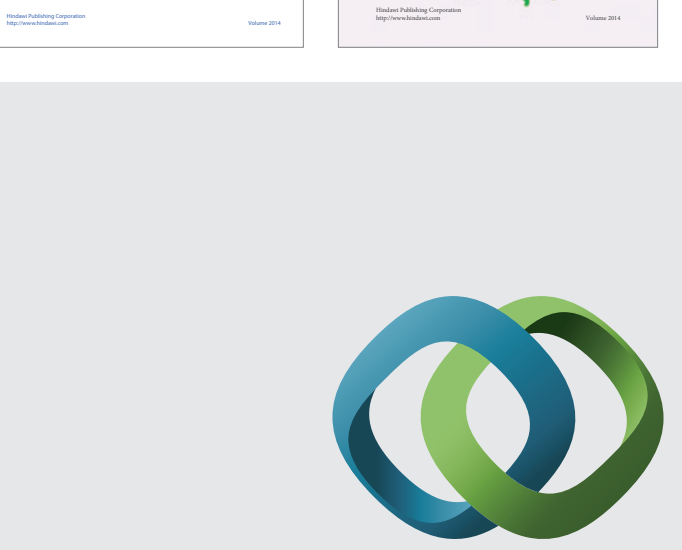

\section{Hindawi}

Submit your manuscripts at

http://www.hindawi.com
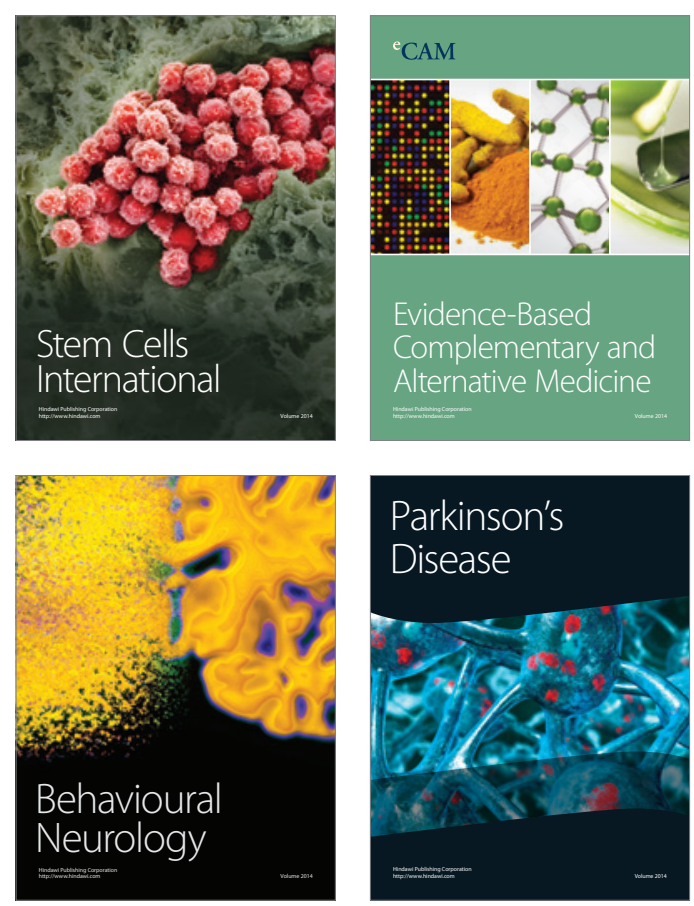

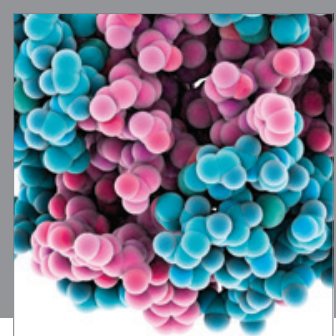

Journal of
Diabetes Research

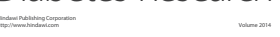

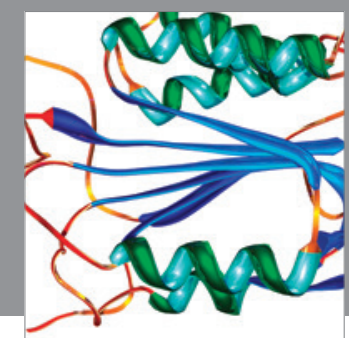

Disease Markers
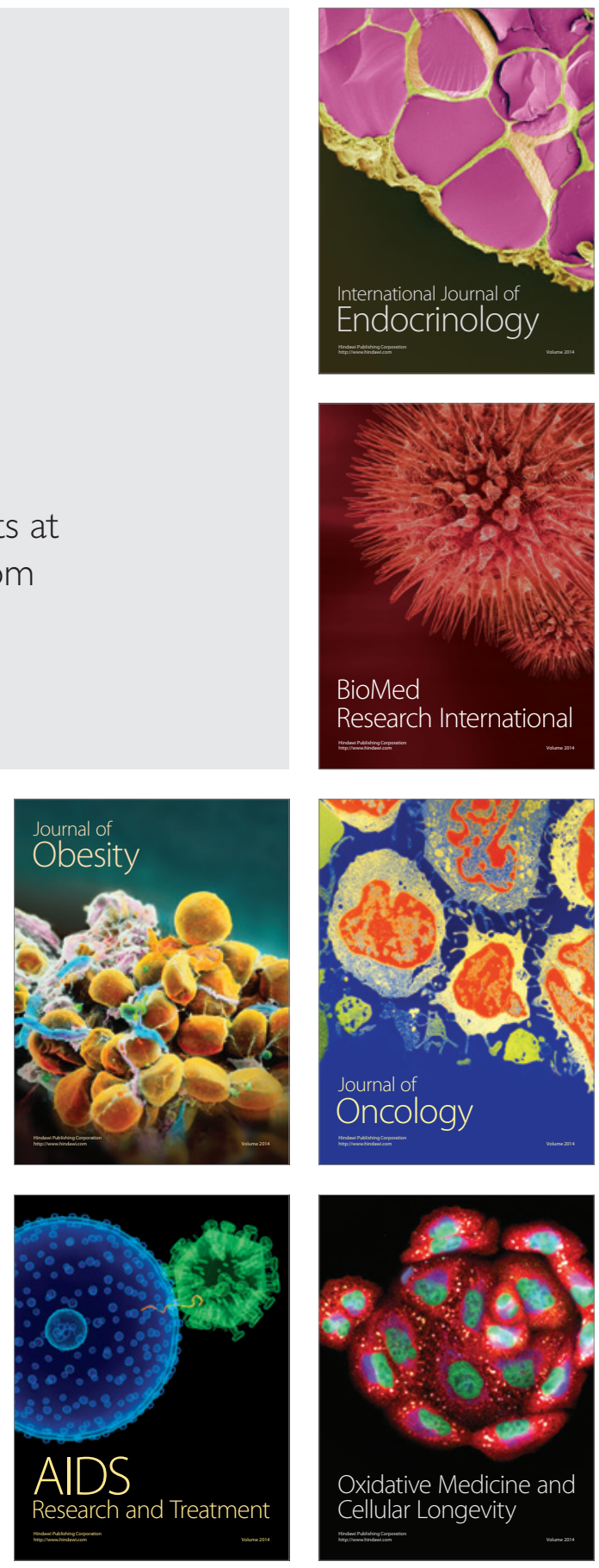